\title{
Intestinal permeability to polyethyleneglycol 600 in Crohn's disease. Peroperative determination in a defined segment of the small intestine
}

\author{
G OLAISON, P LEANDERSSON, R SJÖDAHL, AND C TAGESSON \\ From the Departments of Surgery, Clinical Chemistry, and Occupational Medicine, University Hospital, \\ Linköping, Sweden
}

SUMMARY Ileal permeability to different sized polyethyleneglycols (590-942 dalton PEG) was investigated peroperatively in 11 patients with Crohn's disease and seven with colonic carcinoma. A $15 \mathrm{~cm}$ ileal segment was converted into a tied loop, in which the PEG's were deposited. Absorption from the ileal segment was then measured as six-hour urinary recovery of the PEG dose. Polyethyleneglycol absorption in Crohn's disease was greater than in cancer patients and similar throughout the weight range, but in the cancer patients it was inversely proportional to molecular weight. Thus there was significantly greater absorption of the higher weights $(\geq 678$ dalton) in the Crohn's, than in the cancer patients. The apparently increased permeability of the small intestine in Crohn's disease may be an important factor in its pathogenesis.

Increased intestinal permeability has been suggested as an important pathogenic factor in Crohn's disease..$^{1-4}$ Information on gastrointestinal permeability in Crohn's disease is scanty, however. In some studies different probe molecules were given by mouth, but the observations were conflicting maybe because the part of the gastrointestinal tract in which the probes were absorbed was not defined. To our knowledge, absorption from a defined intestinal segment has not previously been investigated in Crohn's disease.

We therefore measured the permeability of ileal segments during surgery for Crohn's disease or for colonic carcinoma. The test substance was a mixture of different sized polyethyleneglycols.

\section{Methods}

PATIENTS

Seven men and four women with Crohn's disease were investigated. Their age range was $18-49$ (mean 32 ) years. The diagnosis was based on classic radiographic findings and Morson ${ }^{5}$ histological criteria. Ileal inflammation was macroscopically and micro-

Address for correspondence: Gunnar Olaison, MD, Dept of Surgery, University Hospital, S-581 85 Linköping, Sweden.

Received for publication 7 August 1987. scopically manifest in all cases, with no major differences between the different patients. Primary ileocaecal resection was planned for nine patients. The other two had already undergone such surgery (including $50-60 \mathrm{~cm}$ distal ileum), but recurrent preanastomotic disease necessitated revision. The colon carcinoma group comprised three men and four women, aged $30-82$ (mean 67 ) years. All were to undergo right sided hemicolectomy, and all had normal ileum. All had normal serum kreatinin values and no signs of renal disease. The study was approved by the hospital's Ethical Committee.

\section{INTRAOPERATIVE PROCEDURE}

The abdomen was opened and explored. A $15 \mathrm{~cm}$ segment of the most distal part of the ileum (measured at the mesenteric margin) was isolated between double ligatures, for conversion into a tied loop. Before the oral ligatures were tied, a fine catheter (Charrière 8) was inserted into the segment through an incision proximal to the loop. Polyethyleneglycol with average weight 600 (PEG 600; $\left.\mathrm{HO}-\left(\mathrm{CH}_{2}-\mathrm{CH}_{2} \mathrm{O}\right) \mathrm{nH}, \mathrm{n}=13-21\right)$, supplied as Macrogolum by Apoteksbolaget, Sweden, was used as the marker of intestinal permeability. Through the catheter, $4 \mathrm{~g}$ PEG 600 in $10 \mathrm{ml}$ water was introduced 196 
and the oral ligatures were tied. Care was taken to avoid spilling PEG into the abdomen. After deposition the operation was arrested for 20 minutes and the planned resection, including the isolated ileal segment, was then carried out. Previous pilot tests had shown that $10 \mathrm{ml}$ fluid could easily be introduced into a $15 \mathrm{~cm}$ segment of ileum without causing distension, even in the presence of chronic ileal inflammation.

The time from deposition of PEG to completed resection was similar in both patient groups. Thus the time range of exposure to PEG was 40-150 (mean 75) minutes in the Crohn's group and 45-119 (75) minutes in the colon carcinoma group. The urinary output was collected for six hours from the time of PEG deposition. The urine was frozen at $-20^{\circ} \mathrm{C}$ and subsequently analysed for content of PEG. The methods for extraction and analysis of PEG were previously described. ${ }^{6}$

\section{STATISTICAL ANALYSIS}

Results are expressed as mean (SE) of the mean. The Wilcoxon's rank sum test, corrected for ties, was used for statistical evaluation, with $\mathrm{p}<0.05$ accepted as significant.

\section{Results}

The urinary recovery of the different sized PEGs is summarised in Table 1 and the Figure. In some cases no PEG, in particular of the larger sizes, was detectable in the urine. To avoid falsely low means, and to permit statistical evaluation, nondetectable PEG was coded as $0.05 \%$, which was the lowest measurable value for absorption of any PEG.

The patients with colon carcinoma had little urinary excretion of all tested PEG sizes, and also

Table 1 Urinary recovery of different-sized PEG after ileal load in patients with colon carcinoma or Crohn's disease.

\begin{tabular}{|c|c|c|c|}
\hline \multirow{2}{*}{$\begin{array}{l}\text { Molecular } \\
\text { weight } \\
\text { (dalton) }\end{array}$} & \multicolumn{3}{|c|}{ Urinary 6-hour recovery (\%o dose), mean (SE) } \\
\hline & $\begin{array}{l}\text { Colon carcinoma } \\
\text { Patients }(n=7)\end{array}$ & $\begin{array}{l}\text { Crohn's disease } \\
\text { Patients }(n=11)\end{array}$ & $\begin{array}{l}\text { Significance of } \\
\text { difference }(2- \\
\text { tailed p values) }\end{array}$ \\
\hline 590 & $(0 \cdot 45(0 \cdot 05)$ & $1 \cdot 28(0 \cdot 37)$ & $>0 \cdot 05$ \\
\hline 634 & $(0 \cdot 40(0 \cdot 10)$ & $1 \cdot 08(0 \cdot 43)$ & $>0 \cdot 05$ \\
\hline 678 & $0 \cdot 38(0 \cdot 22)$ & $1 \cdot 33(0.52)$ & $<0 \cdot 01$ \\
\hline 722 & $0.12(0.02)[2]$ & $1 \cdot 20(0 \cdot 51)$ & $<0 \cdot(001$ \\
\hline 766 & $0.10(0.02)[3]$ & $1 \cdot 16(0 \cdot 59)$ & $<0 \cdot(0) 1$ \\
\hline 810 & $0 \cdot 10(0 \cdot 03)[4]$ & $1 \cdot 11(0 \cdot 60)$ & $<0 \cdot(x) 1$ \\
\hline 854 & $0.08(0 \cdot 02)[5]$ & $1 \cdot 23(0 \cdot 62)$ & $<0 \cdot(001$ \\
\hline 898 & $0 \cdot 06(0 \cdot 01)[5]$ & $1 \cdot 17(0 \cdot 69)[1]$ & $<0 \cdot(01$ \\
\hline 942 & $0 \cdot 05(0 \cdot 00)[7]$ & $1 \cdot 20(0 \cdot 61)[2]$ & $<0 \cdot(01$ \\
\hline
\end{tabular}

Figures in square brackets denote number of patients with no $(<0 \cdot 05 \%$ of given dose $)$ recovery of relevant size.

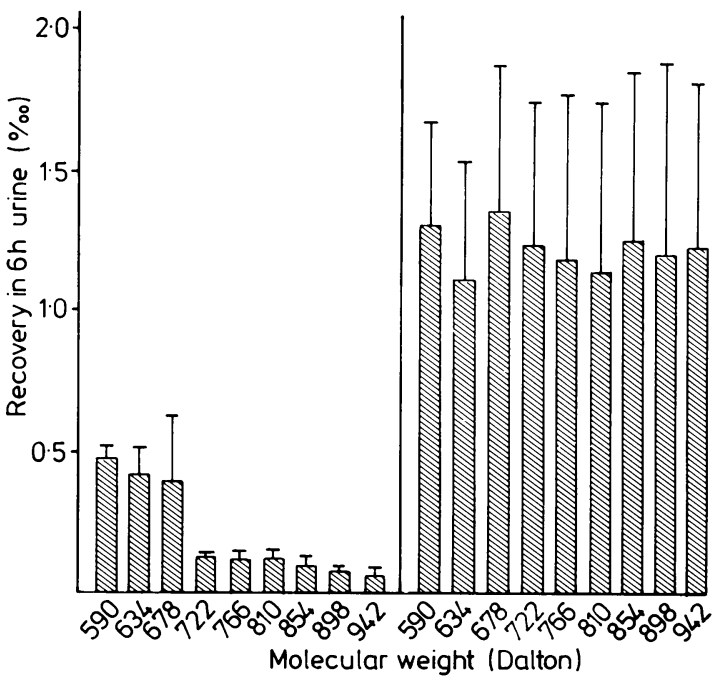

Figure Absorption molecular weight profiles for different sized PEG (590-942 dalton) in patients with colon carcinoma (left) or Crohn's disease (right). Per cent absorption of each molecular weight component was assessed from the urinary recovery over six hours following deposition of $4 \mathrm{~g}$ PEG 600 in an isolated ileal segment. Vertical lines indicate standard error of the mean.

showed decreasing excretion with rising molecular weight of PEG.

In Crohn's disease, the mean urinary excretion of PEG was always greater than in the carcinoma patients, and showed little variation according to molecular weight. The intergroup differences in PEG absorption were significant in the 678-942 dalton range.

There were no differences in six hour urine volume between the two groups, Crohn patients excreted 391

Table 2 Ileal permeability indices in patients with colon carcinoma or Crohn's disease

\begin{tabular}{|c|c|c|c|}
\hline \multirow{2}{*}{$\begin{array}{l}\text { Molecular } \\
\text { weight } \\
\text { ratio }\end{array}$} & \multicolumn{3}{|c|}{ Permeability indices, means (SE) } \\
\hline & $\begin{array}{l}\text { Colon carcinoma } \\
\text { Patients }(n=7)\end{array}$ & $\begin{array}{l}\text { Crohn's disease } \\
\text { Patients }(n=I 1)\end{array}$ & $\begin{array}{l}\text { Significance of } \\
\text { difference (2- } \\
\text { tailed p values) }\end{array}$ \\
\hline $634 / 590$ & $0.92(0.22)$ & $0.90(0 \cdot 13)$ & $>0.05$ \\
\hline $678 / 590$ & $0.84(0.43)$ & $0.96(0.12)$ & $<0.05$ \\
\hline $722 / 590$ & $0.31(0.08)$ & $0.89(0 \cdot 12)$ & $<0 \cdot 01$ \\
\hline $766 / 590$ & $0 \cdot 26(0 \cdot 08)$ & $0.94(0 \cdot 16)$ & $<0 \cdot 01$ \\
\hline $810 / 590$ & $0.26(0.09)$ & $0.86(0 \cdot 18)$ & $<0 \cdot 01$ \\
\hline $854 / 59()$ & $0.23(0 \cdot 10)$ & $0.90(0 \cdot 17)$ & $<0 \cdot(01$ \\
\hline $898 / 590$ & $0 \cdot 16(0 \cdot 04)$ & $0.76(0.17)$ & $<0 \cdot(01$ \\
\hline $942 / 590$ & $0 \cdot 12(0 \cdot 01)$ & $0.75(0.18)$ & $<0 \cdot() 1$ \\
\hline
\end{tabular}

Calculated from data in Table 1 (permeability for individual PEG sizes/ value for PEG 590). 
(228) $\mathrm{ml}$ and patients with colon carcinoma 656 (317) $\mathrm{ml}, \mathrm{p}>0 \cdot 05$.

Permeability indices, for evaluating mucosal selectivity to different-sized molecules, were constructed by dividing the absorption values for the various PEG weights 634-942 by the value for PEG 590 . The ratios thereby obtained (Table 2) were generally higher in Crohn's disease than in colon carcinoma.

\section{Discussion}

Most investigations of gastrointestinal permeability in man are performed after the subjects have ingested various probe molecules. Discordance of results then probably depends on differing routes of uptake for different test substances. ${ }^{7}$ It is nevertheless likely that such tests predominantly reflect absorption in the proximal part of the small intestine, where permeability is much greater than in the distal part. ${ }^{.10}$

Patients with Crohn's disease were reported to have increased intestinal permeability to orally administered lactulose, but impaired absorption of mannitol. ${ }^{12}$ Uptake of radiolabelled Cr-EDTA was increased in Crohn's disease of the small intestine, but appeared to be unaffected in Crohn's colitis, whereas radiolabelled Tc-DPTA showed increased absorption in both types of involvement, with no difference between the two. ${ }^{1314}$ In earlier investigations with ingested PEG, we found that patients with ileocaecal Crohn's disease had impaired absorption of both PEG 400 and PEG 1000, and also diminished selectivity of the intestinal mucosa against larger molecules. ${ }^{1015} 16 \mathrm{~A}$ recent report described increased intestinal permeability to oral PEG 400 in Crohn's disease patients and in their clinical healthy relatives. ${ }^{17}$

Investigations using peroral probe molecules thus do not reveal the site of absorption, inflamed or otherwise, in the intestine. Our method of measuring permeability intraoperatively, in an intestinal segment converted into a tied loop, circumvents this problem. To our knowledge, no previous investigator has clearly shown increased permeability in a well defined, inflamed segment of intestine in man.

Although the duration of exposure to probe molecules was relatively short, the absorption of almost all sizes was sufficient for identification in urine in the patients with Crohn's disease. In the patients with colon carcinoma, the PEG uptake in general was less and in regard to larger molecules it was frequently insufficient for detection in the urine. Despite the relatively small numbers of patients, we thus showed significantly increased permeability to PEG, in at any rate the 678-942 dalton range, in Crohn's disease as compared with colon carcinoma. We also confirmed our earlier findings ${ }^{1016}$ of diminished selectivity of the mucosal barrier in Crohn's disease, permitting larger molecules to be absorbed in amounts almost equalling the uptake of small ones. The intergroup differences in permeability indices were further indications of this mucosal alteration. Our findings accord with an investigation of exsorption of intravenous polyvinyl $v$ pyrrolidone (mean molecular weight 33000 dalton) into the lumen of an intubated, inflamed segment of small intestine in Crohn's disease, which showed increased exsorption and loss of selectivity of the mucosal barrier. ${ }^{18}$

Derangement of mucosal barrier function has been suggested as a prime factor in the development of chronic inflammatory bowel disease. ${ }^{-4}$ A permeable mucosa would permit absorption of microbial and dietary antigen, and this could initiate an inflammatory reaction or perpetuate and potentiate an already existing inflammation. The increased permeability of small intestine in Crohn's disease showed in the present study could have been secondary to the inflammatory process and attributable to mucosal ulcerations. Micro-ulcerations, however, have been found in otherwise non-inflamed mucosa in patients with Crohn's disease. ${ }^{19}$ The possibility cannot be excluded that increased intestinal permeability is a primary event in Crohn's disease and an important factor in development of the inflammatory process.

This study was aided by grants from Östergötland County Council (Östergötlands läns landsting) and the Medical Research Board of the Swedish Life Insurance Companies (Svenska livförsäkringsbolagens nämnd för medicinsk forskning), and by grant B86-17X-05893-06A from the Swedish Medical Research Council (MFR).

\section{References}

1 Gebbers JO, Otto HF. Alterations of the intestinal mucosal block in ulcerative colitis and Crohn's diseaseImmunological and ultrastructural findings, and considerations of the pathgenesis. Klin Pädiatr 1985; 197: 341-8.

2 Hodgson HJF, Potter BJ, Jewell DP. Immune complexes in ulcerative colitis and Crohn's disease. Clin Exp Immunol 1977; 29: 187-96.

3 Ward M. The pathogenesis of Crohn's disease. Lancet 1977; 4: 903-5.

4 Walker WA, Isselbacher KJ. Uptake and transport of macromolecules by the intestine. Possible role in clinical disorders. Gastroenterology 1974; 67: 531-50.

5 Morson BC. Histopathology of Crohn's disease. Proc $R$ Soc Med 1968; 61: 79-81.

6 Tagesson C, Andersson PÅ, Andersson T, Bolin T, Källberg M, Sjödahl R. Passage of molecules through the wall of the gastrointestinal tract - Measurement of intestinal permeability to polyethyleneglycols in the 634- 
1338 Dalton range (PEG 1000). Scand J Gastroenterol 1983; 18: 481-6.

7 Anonymous. Intestinal permeability. [Editorial]. Lancet 1985 ; i: $256-8$.

8 Chadwick VS, Phillips SF, Hofmann AF. Measurements of intestinal permeability using low molecular weight polyethyleneglycols (PEG 400) - II. Application to normal and abnormal permeability states in man and animals. Gastroenterology 1977; 73: 247-51.

9 Loehry CA, Kingham J, Baker J. Small intestinal permeability in animals and man. Gut 1973; 14: 6838.

10 Olaison G, Sjödahl R, Tagesson C. Decreased gastrointestinal absorption of peroral polyethyleneglycols (PEG 1000) in Crohn's disease - A sign of jejunal abnormality. Acta Chir Scand 1987; 153: 373-7.

11 Pearson ADJ, Eastham EJ, Laker MF, Craft AW, Nelson R. Intestinal permeability in children with Crohn's disease and coeliac disease. Br Med J 1982; 285: 20-1.

12 Ukabam SO, Clamp JR, Cooper BT. Abnormal small intestinal permeability to sugars in patients with Crohn's disease of the terminal ileum and colon. Digestion 1983; 27: 70-4.

13 Bjarnason I, O’Morain C, Levi AJ, Peters TJ. Absorption of 51-Chromium-labeled ethylenediaminetetraace- tate in inflammatory bowel disease. Gastroenterology 1983; 85: 318-22.

14 Casellas F, Aguade' S, Soriano B, Accarinoi A, Molero $\mathrm{J}$, Guarner L. Intestinal permeability to ${ }^{49 \mathrm{~m} T c-d i e t h y l e-}$ netriaminopentaacetic acid in inflammatory bowel disease. Am J Gastroenterol 1986; 81: 767-70.

15 Heuman R, Sjödahl R, Tagesson C. Passage of molecules through the wall the gastrointestinal tract Intestinal permeability to polyethyleneglycol 1000 in patients with Crohn's disease. Acta Chir Scand 1982; 148: $281-4$.

16 Magnusson K-E, Sundqvist T, Sjödahl R, Tagesson C. Altered intestinal permeability to low-molecular weight polyethyleneglycols (PEG 400) in patients with Crohn's disease. Acta Chir Scand 1983; 149: 323-7.

17 Hollander D, Vadheim CM, Brettholz E, Petersen GM, Delahunty TJ, Rotter J. Increased intestinal permeability in Crohn's disease patients and their relatives: An etiological factor? Gastroenterology 1986; 90: 1462.

18 Kingham JGC, Loehry CA. Selectivity of small intestinal exudate in celiac disease and Crohn's disease. Dig Dis 1978; 23: 33-8.

19 Rickert RR, Carter HW. The 'early' ulcerative lesion of Crohn's disease: Correlative light- and scanning electron-microscopic studies. J Clin Gastroenterol 1980; 2: 11-9. 